Volume 10, No 2, julho-dezembro 2014, Jataí-GO | ISSN: 1807-9342 DOI: 10.5216/rir.v10i2.30155 
Revista Itinerarius Reflectionis - UFG.

Volume 10, No 2, julho-dezembro 2014, Jataí-GO.

Semestral.

ISSN: $1807-9342$

\section{Universidade Federal de Goiás}

\section{Reitor}

Orlando Afonso Valle do Amaral

\section{Vice-Reitor}

Manoel Rodrigues Chaves

Pró-Reitoria de Graduação

Luiz Mello de Almeida Neto

\section{Regional Jataí}

Diretor: Wagner Gouvêa dos Santos

\section{Editores Responsáveis}

Eveline Borges Vilela-Ribeiro

José Sílvio Oliveira

Vânia Ramos Rodrigues 


\section{Sumário}

Formação humana e música: um estudo sob a ótica de

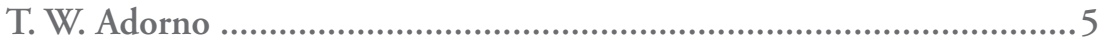

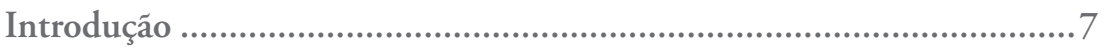

Aspectos da Música na Civilizaçáo Ocidental .....................................7

"Sobre Música Popular”: uma breve abordagem.................................................. 14

Aspectos da Música na Civilização Ocidental Sob A Ótica de Adorno ................ 19

Consideraçốes Finais ..............................................................................24

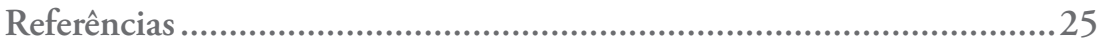




\title{
FORMAÇÁO HUMANA E MÚSICA: UM ESTUDO SOB A ÓTICA DE T. W. ADORNO
}

\author{
Cristiano Aparecido da Costa \\ Doutorando em Educação pela Faculdade de \\ Educaçấo da Universidade Federal de Goiás \\ Docente da área de música do Instituto Federal de Goiás \\ cristianotrp@hotmail.com
}

\section{Resumo}

O objetivo deste estudo é refletir sobre a influência da música na formação humana. O principal referencial teórico é T. W. Adorno. A análise foi baseada em seu texto "Sobre Música Popular”. Duas categorias principais foram norteadoras: estandardização e pseudo-individuação. Este artigo está estruturado em três partes que visam, sob a ótica de T. W. Adorno, relacionar aspectos sócio-históricos da música ocidental com aspectos da sociedade atual.

Palavras-chave: Música; Formação Humana; Educação; Teoria Crítica.

Training human and music: a study under optics of T. W. Adorno

\section{Abstract}

The aim of this paper is to study the influence of music on human formation. The main theoretical framework is the work of T.W. Adorno. The analysis was based on his text "On Popular Music". Two main categories were used as guidelines: standardization and pseudo-individualization. This article is structured in three parts that, under of T.W. Adorno's perspective, intend to relate socio-historical aspects of Western music with aspects of contemporary society.

Keywords: Music; Human Formation; Education; Critical Theory 
Vol. 10, № 2, julho-dezembro 2014 


\title{
Introdução
}

\begin{abstract}
A proposta deste trabalho é fazer um estudo sobre a influência da música na formação humana. $\mathrm{O}$ estudo será baseado, principalmente, no texto "Sobre Música Popular" de T. W. Adorno buscando evidenciar duas categorias por ele desenvolvidas, que nos parece fundamentais para entender o papel da música na sociedade. As categorias destacadas são estandardização e pseudo-individuação. Tais categorias serão relacionadas ao contexto sócio-histórico da música em que a construção do conhecimento musical se encontra diretamente ligado às tramas estabelecidas entre diferentes áreas do conhecimento que contribuem para constituição do indivíduo.

$\mathrm{O}$ texto será estruturado em três partes que são importantes para complementação das ideias. A primeira é um estudo pontual de aspectos sócio - históricos da música buscando traçar seu desenvolvimento técnico na civilizaçâo ocidental. A segunda é um estudo direto de algumas partes do texto "Sobre Música Popular" com objetivo de ressaltar e entender as categorias citadas anteriormente. A terceira é um contraponto entre as partes anteriores para situar as ideias de Adorno no contexto sócio - histórico da música em relação à sociedade.
\end{abstract}

\section{Aspectos da Música na Civilizaçáo Ocidental}

É indispensável, aqui, para uma melhor compreensão dos aspectos da música na civilização ocidental, refletirmos sobre a concepção de música espontânea e música elaborada, popular e séria, como expóe Adorno (1986). Isso dará um maior suporte, nesse estudo, tendo em vista a pouca preocupação conceitual expressa por quem apreende tal manifestação artística.

Não existe nenhum fato espontâneo dentro de uma cultura, mas fatos que passam de geração em geração e que até mesmo podem ser acrescidos de novas ideias ou de novas maneiras de fazer. Assim falamos de música espontânea (popular) como sendo toda aquela praticada em qualquer grupo 
social feita através das experiências do grupo, desta forma, independe de nível de conhecimentos. Qualquer pessoa canta seus próprios versos ou versos de outros, se acompanha em um violão ou outro instrumento porque gosta de cantar, porque está alegre ou triste, enfim, esta é uma maneira da pessoa se comunicar com seu próprio grupo. Todos nós conhecemos, por exemplo, pessoas que 'tocam violão de ouvido'. Conhecemos também na cultura brasileira os repentistas que cantam estórias em romanceiros. Tudo isso são músicas espontâneas no sentido de que milenarmente passam de pai para filho o aprendizado dos instrumentos e a maneira de cantar. $\mathrm{O}$ estudo e registro dos fatos culturais, que embasam essas informaçôes, acontecem a partir da segunda metade do século XIX com o advento das ciências sociais.

Por outro lado, desde que se conhece o mundo civilizado há uma preocupação humana com o 'bem fazer' ou a produção de objetos mais bem acabados, por exemplo, a arquitetura e escultura grega ou o canto do trovador medieval. Nos primeiros a perfeição simétrica das formas, no segundo o cuidado no cantar e versificar suas baladas que levam as primeiras identificaçóes das línguas europeias. Estamos falando de arte que, para proporcionar uma comunicabilidade mais ampla, se preocupa com um desenvolvimento técnico, o que revela níveis de erudição. Encerra-se ai uma possível linha divisória da música: ser espontânea ou elaborada (séria). Qualquer outra terminologia que se usa hoje tais como música popular, música clássica, música erudita, MPB e etc. são forjadas no sentido de classificar e fragmentar as manifestaçóes.

Discorreremos a seguir sobre a música como manifestação artística e cultural na civilização ocidental. Nesse sentido buscaremos relacionar acontecimentos históricos a acontecimentos musicais, de forma pontual, de períodos bem definidos: período medieval, renascentista, barroco, clássico, romântico e pós-romântico ${ }^{1}$.

1 A musicologia pontua como períodos aproximados da história da musica ocidental a Idade média que vai até 1.450 , a renascença de 1.450 a 1.600 , o Barroco de 1.600 a 1.750, o Clássico de 1.700 a 1.800 e o Romantismo de 1.800 a 1.900. 
A primeira manifestação cultural da civilização ocidental foi o canto do cristão primitivo. De acordo com Grout e Palisca (2007), no início do cristianismo, reunióes eram feitas, ainda escondidas, para praticar cultos. Esse cristão, por uma decisão estética, determinava que o seu canto não teria nenhum acompanhamento instrumental e que o impulso rítmico seria apenas do texto a ser cantado, da fala. Esse canto naturalmente se processava nos modos gregos ${ }^{2}$ os quais, eram a base de todo canto da região. Não havia uma escrita musical e esse canto que serviu nos cultos e nas práticas em todas as regióes em que esses cristãos atuavam estão na cultura ocidental até hoje conhecido como canto gregoriano pela tentativa do Papa Gregório Magno (sec. VI) de sistematizá-lo.

Grout e Palisca (2007) relatam que a certa altura os padres pegaram alguns desses cantos da tradição como repertório para cantar em seu culto. Da observação sobre a afinação desses cantos percebe-se a possibilidade de construir música em dois planos simultâneos. Esta foi uma grande invenção na música ocidental. Desde esse acontecimento se desenvolve a polifonia com suas regras de possibilidades de movimento.

A igreja católica medieval exerceu forte influência na população por meio da música. Por volta do século $\mathrm{V}$ ao $\mathrm{XV}$ a conquista do poder foi uma crescente. $\mathrm{O}$ poder social, o poder político, o poder jurídico e o poder econômico sofreram fortes influências. Com um estilo de música que reforçava a influência da palavra sobre a melodia e sobre o ritmo os fiéis eram levados à sensação de simplicidade e humildade. O objetivo da música cristã era destacar a palavra de Deus. A mensagem a ser transmitida deveria alcançar os coraçóes. Assim, a igreja com maior facilidade se fazia ouvir nas decisôes da sociedade.

Nesse sentido, Raynor (1981) discutindo sobre a Igreja Medieval coloca que

2 Modos ou escalas são ordenaçóes sonoras da linguagem musical equivalentes ao alfabeto para linguagem escrita. 
A Igreja cristã utilizou a música, como o culto pagão o fizera, para fins de uma atmosfera extraterrena que ela podia criar, e para afastar o culto do reino da experiência e sentimento subjetivos pessoais. O canto da Igreja católica devia ser a voz da Igreja, e não a de um crente individual: a recitação de rezas, liçóes, epístolas e evangelhos, com suas formulas de entonação para assinalar a pontuaçáo, como os cantos de salmos ou a austera alternância da participação da congregação na Missa, tinha por fim dar objetividade às palavras que podiam muito facilmente cair no sentimento pessoal subjetivo (RAYNOR, 1981, p. 26).

No que se refere à música profana no ocidente, não se tem documentos que falam de seu aparecimento antes dos Trovadores (sec. XII). As baladas trovadorescas são de tal importância que não só em música, mas em literatura se estuda como a principal fonte de formaçáo das línguas europeias. O canto dos Trovadores, a princípio monódicos, logo se torna polifônico sob a influência do canto da igreja. Como característica desses artistas, pode-se dizer que "a substância poética e musical de trovadores e troveiros não é, regra geral, muito profunda, mas as estruturas formais utilizadas denotam grande variedade e engenho" (GROUT; PALISCA, 2007, p. 85). Além disso, é importante citar, as cantigas com temas de amor e as cantigas de gesta eram predominantes. O que reforça questóes políticas e morais e textos que são debates e discussões (GROUT; PALISCA, 2007).

A música na renascença tanto sacra como profana é polifônica. É sabido que, além dos salóes, em qualquer taberna em que as pessoas se reuniam para beber cantavam em polifonia. A renascença se caracteriza, principalmente, pela valorização do profano. Algumas ideias musicais são, gradativamente, aceitas nesse período. Dentre elas a inserção de dissonâncias e a alteração nos modos com objetivo de uma maior tonalização ${ }^{3}$ (GROUT; PALISCA, 2007). O conhecimento em música estava em pleno desenvolvimento técnico, estilístico e interpretativo, o que contribuía para a própria formação humana. Isso pode ser percebido em relação à música palaciana. No ideal

3 Tonalizar (Tonalidade) é chegar a um ponto de conclusão, superação de tensôes de ideias musicais, o equivalente à pontuaçáo nas frases da linguagem escrita. 
do Renascimento, como coloca Raynor (1981, p. 91), "admitia-se em geral a doutrina de que uma compreensão de música era necessária e vantajosa do ponto de vista educacional, porque a música fazia parte do mundo do Homem Universal (...)".

Talvez, para uma visão simplista e vazia da formação humana, um maior destaque pode ser dado ao papel da música na sociedade aristocrática. É o que expóe Raynor

A música naturalmente se prestava à ostentação. Assim como acrescentava pompa e esplendor às cerimonias da corte de um rei, a nobreza glorificava as suas vidas cercando-se de semelhante magnificência. Desde a utilização funcional da música como acréscimo da vida pomposa até a aceitação da arte como atividade necessária do homem civilizado foi um passo que levou muito tempo; no entusiasmo intelectual do Renascimento, a música adquiriu seu verdadeiro lugar como uma das realizaçóes necessárias e mais louváveis do homem civilizado (RAYNOR, 1981, p. 91).

Na música dramática (teatro e música) - barroca, o personagem canta a uma só voz. Para o ouvido culturalmente polifônico esse canto monódico não é expressivo. Daí a necessidade de se desenvolver uma técnica de acompanhar o canto com instrumento musical. Essa técnica que aparece no século XVII é o que se chama de harmonia ${ }^{4}$. A partir de então a música no ocidente se evolve dentro da prática polifônica e harmônica. Nisso o desenvolvimento da orquestra, da música sinfônica e da música dramática (GROUT; PALISCA, 2007).

No século XVIII, por imposição das cortes, que queriam um estilo de música muito previsível, estilo esse que criava uma sensação de plenitude e felicidade aos nobres para qual essa música era feita, é determinado uma técnica de harmonia baseada em três funçôes: tônica que é o repouso, dominante que é o ponto de tensão e a subdominante que cria sensação

4 Nos referimos aqui a harmonia como técnica musical onde blocos sonoros (acordes) se encadeiam servindo de base para uma linha melódica principal. 
de continuidade ${ }^{5,}$ 6. Toda a música ocidental monódica, polifônica ou harmônica acontece, como na fala, em frases que caminham para pontos tonais, continuação ou conclusão.

A música do chamado período clássico trazia como bagagem uma racionalidade característica, expressa na organização de seus elementos. Como exemplo, podemos citar a simetria entre as partes e uma grande preocupação com o equilíbrio de intensidade e timbre do som. De acordo com Grout e Palisca (2007)

A estética do início do século XVIII defendia que a função da música, bem como das outras artes, consistia em imitar a Natureza, oferecer ao ouvinte imagens sonoras agradáveis da realidade. A música não devia imitar propriamente os sons da Natureza, mas antes os sons da fala, especialmente na medida em que estes exprimiam os sentimentos da alma (...) (GROUT; PALISCA, 2007, p. 479).

Citando as ideias de Rousseau, os mesmos autores dizem que a música "Devia imitar um canto falado primitivo que se presumia ser a linguagem natural do homem, ou então poderia de algum modo imitar os próprios sentimentos, mas não necessariamente através da imitação da fala” (GROUT; PALISCA, 2007, p. 479).

Além disso, Grout e Palisca (2007) relatam que

[...] a música das luzes devia ir ao encontro dos ouvintes, e não obrigá-lo a fazer um esforço para entender a sua estrutura. Devia cativar (através de sons agradáveis e de uma estrutura racional) e comover (através da imitaçâo dos sentimentos), mas não surpreender em demasia (através de uma excessiva elaboração) e ainda menos causar perplexidade (através de um excesso de complexidade). A música, como <<arte de cativar

5 Hoje, qualquer pessoa que aprende música de "ouvido" aprende no violăo, por exemplo, três posiçóes básicas que acompanha qualquer música que queira cantar. Essa simplificação se remete a determinação da prática harmônica do século XVIII.

6 O tratado de harmonia de Jean Felipe Rameau publicado em 1722 contendo todas essas ideias é o primeiro tratado de harmonia publicado (STRUNK, 1965). 
através da sucessão e combinação de sons agradáveis >> ${ }^{7}$, devia evitar as complexidades contrapontísticas que só alguns eleitos seriam capazes de apreciar (GROUT; PALISCA, 2007, p. 479 e 480).

Do contexto histórico, desse período na Europa, é perceptível a incorporação de ideias na construção musical. O Iluminismo, suporte para a Revolução Francesa, é a maior comprovação dessa afirmação. Pensamento esse assim descrito por Hobsbawm:

Um individualismo secular, racionalista e progressista dominava o pensamento "esclarecido". Libertar o indivíduo das algemas que o agrilhoavam era o seu principal objetivo: do tradicionalismo ignorante da Idade Média, que ainda lançava sua sombra pelo mundo, da superstição das igrejas (distintas das religião "racional" ou "natural"), da irracionalidade que dividia os homens em uma hierarquia de patentes mais baixas e mais altas de acordo com o nascimento ou algum outro critério irrelevante. A liberdade, a igualdade e, em seguida, a fraternidade de todos os homens eram seus slogans (HOBSBAWM, 2011, p. 48).

O século XIX, na música (Romantismo), traz em seu bojo características que valorizam fortemente a subjetividade. $\mathrm{O}$ material para construção da música, herdado do classicismo, continua sendo a harmonia e polifonia. Ele é proposto em organizaçóes que prevê um desligamento do mundo concreto dos objetos. O que de acordo com Grout e Palisca (2007) confere à música a condição de abstrair no sujeito o fluxo das impressóes, dos pensamentos e das emoçóes. Em afirmação, Grout e Palisca (2007, p. 577) dizem que “[...] a música desse período ultrapassou constantemente as fronteiras da racionalidade, aventurando-se no terreno do inconsciente e do sobrenatural".

O século XIX foi uma época de progresso e revolução, o que também refletiu nas construçôes musicais. Compositores como Beethoven, Wagner

7 O autor faz essa citação de Burney, <<Essay on musical criticism >>, introdução ao livro III da sua General History of music, ed. Frank Mercer, Nova Iorque, 1957,2,7. 
e Tchaikovsky são exemplos de artistas que representaram em obras acontecimentos sociais daquele período. A partir da estrutura harmônica-clássica os compositores para expressar as impressóes, pensamentos e emoçóes buscam na modulação ${ }^{8}$ a imprevisibilidade que se quer causar no ouvinte. A música tonal dá chance de se criar texturas mais ou menos previsíveis e até mesmo texturas saturadas de previsibilidade. Essa progressiva prática de modulação leva a saturação do sistema tonal. Naturalmente compositores buscam outras soluçóes, o que desemboca no século XX a ideia de música atonal ${ }^{9}$, da valorização do timbre e da quebra dos ritmos periódicos elementos estes que trazem mais imprevisibilidade nas manifestações musicais.

É importante lembrar que a partir da metade do século XIX, com o advento das ciências sociais, começa-se a estudar as manifestaçôes culturais inclusive a música espontânea. Coincidentemente nessa época começam a aparecer os aparelhos técnicos de arquivo e difusão, o que transformará num futuro muito breve os processos musicais. Os meios de comunicação em massa contribuíram muito para o crescimento do público dos diversos gêneros musicais. $O$ que pode ser citado, mais especificamente, nesse sentido é a ampliação do acesso à grande massa do que será chamado música popular (GROUT; PALISCA, 2007).

\section{“Sobre Música Popular”: uma breve abordagem}

O estudo referente à música popular, desenvolvido por Adorno (1986), é importante, nesse trabalho, no sentido em que ele busca evidenciar aspectos contrários entre a música popular e a música séria. No que foi tomando como referencia elementos musicais e sociais. Assim, foram estabelecidos alguns níveis de elaboração, para a música, que serviram como

8 Modular significa passar de um plano tonal a outro.

9 Atonalidade faz referencia à música sem ponto tonal. O que implica a não resolução das tensões. 
parâmetros. É interessante não esquecer que a análise da música popular foi realizada com base na atualidade do autor.

Como elemento que vem interferir na função da música popular, e que para nós é de fundamental importância, nesse estudo, é citada a estandardização ${ }^{10}$. Tal elemento se torna um problema a partir do momento em que é trabalhado de forma consciente buscando uma previsibilidade excessiva. Nisso a estandardização da música popular, dita por Adorno (1986), é diferente do padrão geral, pela camuflagem, feita em uma fachada construída por especialistas deste tipo de música. A excessiva estandardização na música pode implicar, de acordo com Adorno (1986), em processos de alienação do sujeito. $\mathrm{O}$ que pode ser dito, a nosso ver, principalmente sobre a pseudo-individuação.

Cabe ressaltar nesse momento que na obra de arte é necessário um mínimo de redundância para que se possa perceber a forma. Sendo a música uma arte temporal é pela redundância que o ouvinte, com sua memória imediata, vai relacionar a parte com o todo. O que se condena, e Adorno (1986) reforça, é um excesso de redundância que vem facilitar a audição não instigando o sujeito a novas experiências que contribuem para a construçáo de um conhecimento emancipatório.

Para uma percepção mais clara do que se está falando sobre estandardização Adorno coloca diferentes maneiras de aplicação na música: "[...] os pilares harmônicos de cada hit - o começo e o final de cada parte precisam reiterar o esquema padrão" (Adorno, 1986, p. 116). Esquema esse que, de acordo com a análise do autor, enfatiza fatos harmônicos primitivos não importando o que tenha intervindo em termos da própria harmonia. A sensação é de que tudo está se repetindo. O que implica na exclusão do novo, mesmo que aconteça qualquer variação dentro do já estabelecido.

10 A estandardização da música pode ser entendida, na perspectiva de Adorno (1986), como modelos de ideias musicais que se repetem continuamente. Nisso uma ideia melódica ou trecho melódico, sequencias rítmicas e/ou harmônicas, formas estruturais, dentre outras. 
Outro exemplo pode ser dado quando Adorno fala sobre a relação entre a estrutura geral e o detalhe na música:

O efeito primário dessa relação entre a estrutura geral e o detalhe é que o ouvinte fica inclinado a ter reaçóes mais fortes para a parte do que para o todo. Sua captação do todo náo reside na experiência viva dessa peça concreta de música que ele tenha acompanhado. $\mathrm{O}$ todo é preestabelecido e previamente aceito, antes mesmo de começar a real experiência da música; por isso, quase não parece influenciar a reaçáo dos detalhes, exceto em conferir-lhes graus variados de ênfase (ADORNO, 1986, p. 117).

Em termos da estrutura musical, o que é dito refere-se a diferentes possibilidades. Se uma ênfase muito forte é dada à melodia, com muitas repetições ou uma simplicidade na estrutura rítmica, o ouvinte tenderá a voltar-se para aquela parte. Ou então, se for uma canção e a letra for maçante com pouca informação que se repete o tempo todo, o ouvinte se inclinará apenas para esse detalhe. Com isso, o todo que é justamente a relação entre as partes e que pode instigar novas percepções é esquecido. Em linhas gerais pode-se dizer que "na música popular, a posição é algo absoluto. Cada detalhe é substituível; serve à sua função apenas como uma engrenagem numa máquina” (ADORNO, 1986, p. 118).

Buscando uma comparação com a música séria, Adorno (1986) dá ênfase na importância da relação estrutural das partes com o todo. $\mathrm{O}$ que não é buscado na música popular que enfatiza as partes já que o todo é um standard que já está previamente percebido. Buscando ilustrar essa afirmativa o autor cita duas peças de Beethoven, a Sétima sinfonia e a Apassionata. Delas é comentado sobre a importância fundamental da localização específica de seus temas e a maneira como cada um se desenvolve na peça de maneira a promover o sentido musical da obra. Para o reforço desse comentário Adorno afirma que

[...] em Beethoven e na boa música séria em geral (...) o detalhe contem virtualmente o todo e leva à exposiçáo do todo, ao mesmo tempo em que é produzido a partir da concepção do todo. Na música popular, a relação é 
fortuita. O detalhe não tem nenhuma influência sobre o todo, que aparece como uma estrutura extrínseca. Assim, o todo nunca é alterado pelo evento individual e, por isso, permanece como que à distância, imperturbável, como se ao longo da peça não se tomasse conhecimento dele. Ao mesmo tempo, o detalhe é mutilado por um procedimento que jamais pode influenciar e alterar, de tal modo que ele permaneça inconsequente. Um detalhe musical impedido de desenvolver-se torna-se uma caricatura de suas próprias potencialidades (ADORNO, 1986, p. 119).

É importante ressaltar que a comparação entre música séria e música popular, feita por Adorno (1986), não acontece no sentido de denegrir uma em relação à outra, mas sim de ressaltar a maneira com que a estandardização é trabalhada. Tanto que é dito que pode haver complexidade e simplicidade em ambas as maneiras de se fazer música.

Contudo, além dos aspectos técnicos já discutidos, boa parte da problemática envolvendo a estandardização refere-se a questôes comerciais. Com o objetivo de conduzir a aceitação das pessoas, para o tipo de música em questão, técnicas que simulam as de industrialização para produção em massa são aplicadas em sua construção. Reforçando essa questão, de acordo com Adorno

Embora toda a produção industrial de massa necessariamente resulte em estandardização, a produção de música popular só pode ser chamada de "industrial" em sua promoção e distribuição, enquanto o ato de produzir música do tipo hit ainda permanece num estágio manufatureiro. A produçáo da música popular é altamente centralizada em sua organização econômica, mas "individualista" em seu modo social de produção. A divisão do trabalho entre compositor, harmonizador e arranjador não é industrial, mas simula a industrializaçáo, a fim de parecer mais atualizada, enquanto, na verdade, adaptou métodos industriais para a técnica de sua promoçáa (ADORNO, 1986, p. 121).

Exemplo dessa colocação, Adorno (1986) dá ao falar da Imitação. Segundo ele, pelo fato de ser desenvolvida em um processo competitivo, a música popular ao atingir um grande sucesso era imitada por centenas de 
outras. Imitação de um padrão que acabava se tornando um standard. O que acabou gerando um problema para aqueles que não quiseram seguir o padrão imposto. Esses eram excluídos do mercado por seu próprio posicionamento. Nisso Adorno diz que "os padróes originais, agora estandardizados, evoluíram num percurso mais ou menos competitivo. A concentração econômica em larga escala institucionalizou a estandardização, tornando-a imperativa" (ADORNO, 1986, p. 123).

Consequência de todo esse processo de manipulação e alienação pela audição do ouvinte é o que Adorno (1986) coloca como pseudoindividuação, que para ele é correspondente da estandardização musical. Entendida como o envolvimento estabelecido entre a produçâo cultural de massa e a auréola da livre-escolha tendo como base a estandardização. Expresso de outra forma, para o autor a pseudo-individuação é um processo em que o ouvinte fica enquadrado de modo a esquecer que o que ele escuta já foi escutado por ele, já foi, como Adorno detalha, "pré-digerido".

Como o texto de Adorno tem como base para discussão sobre a música popular o Jazz, esse estilo de música é tomado como exemplo, também nesse momento, para dizer de como é promovida a pseudo-individuação. Sendo o improviso uma das características fundamentais do Jazz, Adorno (1986) o toma para falar dos procedimentos padronizados de individuação. Segundo ele a "pseudo-individuação é prescrita pela estandardização da estrutura" (ADORNO, 1986, p. 123). A falsa ilusão de individualidade, promovida no ouvinte, é constituída na construção musical de modo a ser apreendida sem esforço.

O que Adorno (1986) quer dizer é que o significado da palavra improviso, assim como nos é apresentado, é apenas uma fachada. As várias possibilidades organizadas são previamente construídas falseando a percepção de algo novo. Ou seja, pensar a individualidade a partir do improviso é dar a falsa impressão de que cada indivíduo é único, assim como o improviso. Esse ponto é muito bem detalhado a seguir 
Essa subserviência do improviso à estandardização explica duas principais qualidades sociopsicológicas da música popular. Uma é o fato de que o detalhe permanece abertamente ligado ao esquema subjacente, de tal modo que o ouvinte sempre se sente pisando em solo firme. A escolha, em termos de alteraçóes individuais, é tão estreita que o eterno retorno das mesmas variaçóes é uma sinal reassegurador do idêntico por trás delas. A outra é a função de "substituição" - os traços improvisatórios impedem que sejam tomados como fenômenos musicais em si mesmos. Eles só podem ser percebidos como embelezamentos. É um fato bem conhecido que, em arranjos mais ousados para $j a z z$, notas perturbadoras, tons "sujos" em outras palavras, notas falsas, desempenham um papel conspícuo. São percebidas como estímulos excitantes só por que são corrigidas pelo ouvido para a nota correta. Isso, no entanto, é apenas um exemplo extremo daquilo que acontece menos conspicuamente em toda individuação na música popular. Qualquer ousadia harmônica, qualquer acorde que não caia estritamente dentro do mais simples esquema harmônico, exige ser percebido como "falso", isto é, como um estímulo que carrega consigo a clara prescrição de substituí-lo pelo detalhe correto, ou melhor, pelo puro esquema. Entender música popular significa obedecer a tais comandos ao escutar. A música popular impóe os seus próprios hábitos de audição (ADORNO, 1986, p. 124).

O que se percebe sobre as claras afirmaçóes de Adorno (1986) é que a forma que se tem trabalhado a música popular visa, explicitamente como categorias ideológicas, tais como o gosto e a livre-escolha, reforçar o propósito de camuflar a estandardização, assim como ela é apresentada.

\section{Aspectos da Música na Civilização Ocidental Sob A Ótica de Adorno}

A música na civilização ocidental apresenta várias características que podem ser analisadas no sentido de verificar possíveis influências na formação humana. Pensando a música como uma área de conhecimento, entendemos que ela pode ter tanto um caráter alienante como emancipatório. Partindo desse pensamento e caminhando em um sentido mais amplo, Adorno e Horkheimer (1985, p. 17) afirmam que no "progresso do pensamento, o 
esclarecimento tem perseguido sempre o objetivo de livrar os homens do medo e de investi-los na posição de senhores". Contudo, o que de forma predominante tem acontecido e Adorno e Horkheimer denunciam é que "os homens querem aprender da natureza é como empregá-la para dominar completamente a ela e aos homens" (ADORNO; HORKHEIMER, 1985, p. 17). Assim, com base nessas afirmativas, podemos verificar algumas categorias ideológicas trabalhadas por meio da música no decorrer da história da civilização ocidental.

É importante lembrar que no Ocidente, no decorrer do processo histórico, a música alcançou diferentes níveis de organização. Pautados, a princípio, na fala as possibilidades técnicas, tanto para música secular quanto religiosa, caminharam no sentido de elaboraçôes bastante aprofundadas. Grupos vocais e instrumentais foram formados e aprimorados a partir de novas ideias que foram surgindo. Como descrito anteriormente, no período Medieval e Renascença, o canto e a polifonia foram características fundamentais para desenvolvimento e expressão da música. No período Barroco com a música dramática e instrumental surge a harmonia. A partir do Classicismo a construção musical passa a se pautar em funçóes harmônicas que, junto com a polifonia, reforçam um caráter subjetivo na música do período Romântico. No início do século XX em diante, com a saturação do tonalismo, surge como consequência natural dos processos modulatórios a chamada música atonal.

Tendo em vista essa exposição, entendemos que a música espontânea pode ser tomada como referencia para analisar as características da música no ocidente já que, sobre ela, de forma preliminar, foram apresentadas algumas informações que vão ao encontro de tais características. Também porque compreendemos ser ela uma fonte de onde a "Indústria Cultural" (ADORNO; HORKHEIMER, 1985) vai tirar todas as características citadas como forma de alienação, o que culminará no que Adorno (1986) trata como sendo a música popular. 
Cabe pontuar que, em 1846, William John Thoms publica um artigo definindo o termo folclore em que ele diz ser a ciência que estuda as diferentes manifestaçóes das camadas populares dos países civilizados (LIMA, 1985). Essa dicotomia entre camada popular e países civilizados foi refutada pelos estudos da antropologia. De qualquer modo ficou o pensamento preconceituoso sobre práticas populares nos países civilizados. Uma dessas práticas é a música espontânea da qual já fizemos observaçóes. A partir de então começa a se falar muito de música popular se referindo à música das camadas menos favorecidas.

Lembrando que esse processo se intensificou com a revolução industrial que acontece a partir do séc. XVIII. Nisso, com o desenvolvimento dos meios tecnológicos de comunicação e arquivamento os bens culturais do povo foram associados com os processos de industrialização. O que contribuiu para o surgimento da "indústria cultural" (Adorno; Horkheimer, 1985), essa que se apropria daquilo que é um bem da coletividade, transformando em produtos e associando aos meios de comunicação para inculcar sua aceitação junto às pessoas. Ainda, se apropriando desses bens para transformá-los em produtos alienantes: baratos e descartáveis para ser vendável. A indústria cultural é alienante, pois, não oferece aos indivíduos da sociedade estímulos a novas percepçóes, à livre escolha e à crítica.

Com o aparecimento dos meios de comunicação no final do século XIX e início do século XX a tarefa de levar informaçóes a um maior número de pessoas se tornou um acontecimento muito importante para se moldar e padronizar gostos.

Democrático, o rádio transforma-os a todos igualmente em ouvintes, para entregá-los autoritariamente aos programas, iguais uns aos outros, das diferentes estaçôes. Não se desenvolveu qualquer dispositivo de réplica e as emissóes privadas são submetidas ao controle. Elas limitam-se ao domínio apócrifo dos "amadores", que ainda por cima são organizados de cima para baixo. No quadro da rádio oficial, porém, todo traço de espontaneidade no público é dirigido e absorvido, numa seleção profissional, por 
caçadores de talentos, competiçóes diante do microfone e toda espécie de programas patrocinados. Os talentos já pertencem à indústria muito antes de serem apresentados por ela: de outro modo não se integrariam tão fervorosamente. A atitude do público que, pretensamente e de fato, favorece o sistema da indústria cultural é uma parte do sistema, não sua desculpa (ADORNO; HORKHEIMER, 1985, p. 100 - 101).

Referente à análise proposta cabe destacar que as técnicas musicais desenvolvidas no ocidente são escutadas claramente na música espontânea. Acompanhar de ouvido qualquer melodia em um instrumento harmônico é fazer as três funçóes tonais. Prática essa definida no tratado de Harmonia de Jean Philippe Rameau publicado em 1722. Tratado esse que nada mais é que uma apologia da prática simplificada da música. Uma prática da previsibilidade.

Também o que foi em um momento técnico de uma maneira simplificada passa a ser cultural. Por exemplo, Cantar e fazer um 'contracanto' é cantar e responder. As melodias das músicas espontâneas estão construídas, de modo geral, em padróes repetitivos muito simples, como a repetição de uma mesma melodia em altura diferente. Muito comum é a prática de se cantar simultaneamente a mesma melodia de forma superposta, o que pode ser exemplificado, dentro da nossa cultura, pela música caipira. E que é entendido, a critério de nossa análise, como uma prática polifônica.

Facilmente, nos dois exemplos dados, percebemos a estandardização como critério para aceitação e afirmação das ideias musicais. De maneira mais sistemática, do período Clássico até o final do Romantismo, a música séria foi construída com base nas três funçóes harmônicas. Isso de certa forma implicou em um comodismo para a compreensão daquilo que estava sendo escutado. A quebra de tensôes estabelecidas pelo sistema tonal gerava uma previsibilidade que acomodava o ouvinte. $\mathrm{O}$ não estímulo a novas percepções - ao Novo - reforçava essa aceitação. Para Adorno (1986, p. 131) "o sentido musical é o Novo - algo que não pode ser subsumido sob a 
configuração do conhecido, nem a ele ser reduzido, mas que brota dele, se o ouvinte vem ajudá-lo”.

A previsibilidade da música tonal proporciona ao ouvinte um caráter de identificação com o já conhecido que culmina com sua prévia aceitação. Para Adorno

O momento da efetiva identificação - e efetiva experiência do "é isso!". Ela é alcançada quando a vaga recordação é iluminada por um súbito reconhecimento. É comparável à experiência que se tem quando se está sentado num quarto que tenha sido deixado no escuro e, de repente, a luz se acende de novo. Pelo caráter súbito dessa iluminação, a mobília, tão familiar, adquire, por uma fração de segundo a aparência de ser nova. A espontânea conclusão, de que essa peça é "a mesma que" se ouviu há algum tempo, tende a remover, por um momento, o perigo sempre iminente de que algo seja como sempre foi (ADORNO, 1986, p. 132).

É claro para nós que tanto o uso da polifonia quanto da harmonia e de outras técnicas de construção da música no Ocidente, da forma que se deu, reforçam a análise de Adorno sobre a chamada música popular. $\mathrm{O}$ que culmina com a falsa impressão de individualidade inculcada na cabeça das pessoas. Por exemplo, como dito anteriormente, as cançôes espontâneas já trazem consigo certa facilidade de execução e escuta construída historicamente. Quando as técnicas aplicadas são apropriadas pelas agências promotoras do que passou a se chamar música popular, e aplicadas com objetivo de direcionar a escolha de algo que segue o mesmo padrão, temos ai um processo de formaçâo de uma falsa individualidade. Ou seja, o sujeito escolhe sobre opçóes idênticas. Isso é o que Adorno nos mostra por meio de sua análise:

Um indivíduo defronta-se com uma canção individual que, aparentemente, está livre para aceitar ou rejeitar. Pela promoção e pelo apoio dado à cançáo por agências poderosas, esse mesmo indivíduo fica privado da liberdade de rejeitar, que talvez ainda mantivesse em relação à cançáo individual. Não gostar da canção não é mais a expressão de um gosto subjetivo, mas antes uma rebelião contra a sapiência de uma utilidade pública e uma 
discordância com os milhões de pessoas que assumem dar sustentação àquilo que as agências estão lhes dando. A resistência é encarada como um sinal de má cidadania, como incapacidade de se divertir, como falta de sinceridade do pseudo-intelectual, pois qual é a pessoa normal que poderia se colocar contra essa música normal? No entanto, tal aumento quantitativo de influência, indo além de certos limites, altera fundamentalmente a composição da própria individualidade (ADORNO, 1986, p. 142).

Dessa forma o sujeito, por meio de técnicas para construção musical altamente elaborada no sentido de conduzir pensamentos e açóes, perde a capacidade de escolha e crítica.

\section{Consideraçóes Finais}

Diante da breve análise e pontuais informaçóes sobre a história da música no Ocidente, consideramos que das práticas musicais, foram trabalhados alguns elementos que contribuem para alienação do sujeito. Adorno (1986), em seu texto, faz a análise da música a partir do jazz, mas de forma pontual também traz informações importantes da música séria, isso contribuiu bastante para suas felizes colocaçóes. Das categorias trabalhadas as de estandardização e pseudo-individuação tiveram destaque por dar maior ênfase na relação entre sujeito e objeto e na influência de um sobre outro.

É claro que esse é apenas o início de uma discussão bastante complexa em que a música é um de vários instrumentos de manipulação em uma sociedade de mercado. Por isso, por entender que a música como um artefato aceito e enraizado nas tradiçóes do povo acabou se convertendo como um dos principais canais de imposição ideológica, fizemos uma linha do tempo em que tentamos elucidar as possibilidades que essa manifestação artística pode oferecer. 


\section{Referências}

ADORNO, T. W. Sobre música popular. In: Cohn, G. (org.) Sociologia. São Paulo: Ática, 1986, p. 115-146.

ADORNO, T. W; HORKHEIMER, M. Dialética do Esclarecimento: fragmentos filosóficos. Tradução: Guido Antonio de Almeida. Rio de Janeiro: Jorge Zahar, 1985.

GROUT, D. J.; PALISCA, C.V. História da Música Ocidental. $5^{\mathrm{a}}$ ed. Tradução: Ana Luísa Faria. Lisboa: Gradiva, 2007.

HOBSBAWM, E. J. A Era das Revoluçóes 1789 - 1848. 25a ed. Tradução: Maria Tereza Teixeira e Marcos Penchel. São Paulo: Paz e Terra, 2011.

LIMA, R. T. Abecê do Folclore. 6a ed. Sao Paulo: Recordi, 1985.

RAYNOR, H. História Social da Música: Da Idade Média a Beethoven. Tradução: Nathanael C. Caixeiro. Rio de janeiro: Zahar Editores, 1981.

STRUNK, O. The Baroque Era. New York: Norton e Company, 1965. 
